\title{
Autoeficácia e experiência de professores no uso de tecnologias de informática
}

Title: Self-efficacy and teachers experience in the use of computer technology

\author{
Melissa Picchi Zambon \\ Universidade Federal de São Carlos \\ melissapzambon@yahoo.com.br
}

\author{
Deisy das Graças de Souza \\ Universidade Federal de São Carlos \\ ddgs@ufscar.br
}

\author{
Tânia Maria Santana de Rose \\ Universidade Federal de São Carlos \\ tmsrose@terra.com.br
}

Resumo Apesar dos grandes investimentos governamentais para a implementação de Tecnologias de Informação e Comunicação (TIC) no ensino público brasileiro, seu uso vem sendo pouco explorado. A relação entre professores e computadores é complexa e envolve variáveis como características do contexto, conhecimentos sobre a aplicação da tecnologia, crenças pedagógicas e variáveis psicológicas, dentre as quais, destaca-se a autoeficácia. A autoeficácia computacional docente envolve as crenças do professor quanto à própria capacidade para utilizar tecnologias de informática no contexto educacional e é considerada uma importante preditora do envolvimento dos professores no uso de tais tecnologias. O presente pretendeu verificar se a experiência no uso de um software educacional afeta o grau de informações sobre o uso de computadores e a autoeficácia computacional docente. Participaram do estudo 34 professores do Ensino Fundamental de quatro escolas públicas, divididos em dois grupos. Os professores do Grupo $1(N=9)$ vinham aplicando um programa de ensino individualizado, realizado em computador, enquanto os do Grupo $2(N=25)$ ministravam disciplinas regulares. Todos os professores responderam a um questionário de caracterização e a uma escala para a avaliação da autoeficácia computacional docente. Os professores do Grupo 1 obtiveram índices significativamente mais elevados de autoeficácia computacional docente e uma maior porcentagem deles declarou-se preparada para o uso do computador como ferramenta de ensino. Destaca-se a importância da autoeficácia para o uso efetivo das TIC no contexto educacional e sugerese experiências favorecedoras para seu desenvolvimento nos cursos de formação.

Palavras-Chave: Tecnologias Educativas; Variáveis Psicológicas; Autoeficácia; TIC na Educação.

\begin{abstract}
Despite significant government investment for the implementation of Information and Communication Technologies (ICT) in Brazilian public schools, its use has been little explored. The relationship between teachers and computers is complex and involves variables as context characteristics, knowledge about the application of technology, pedagogical beliefs and psychological variables, such as self-efficacy. The computer self-efficacy beliefs involves teacher' beliefs about their own ability to use computer technologies in educational contexts and are considered an important predictor of teachers involvement in the use of such technologies. This study intended to determine whether the experience of using an educational software affects the degree of information about the use of computers and teacher's computer self-efficacy. Study participants were 34 elementary school teachers from four schools divided into two groups. Teachers in Group $1(N=$ 9) had been applying a program of individualized instruction, held on computer, while teachers in Group $2(N=25)$ teach regular subjects. All teachers answered a characterization questionnaire and a scale for assessing teacher computer self-efficacy. Teachers in Group 1 had significantly higher levels of computer self-efficacy and a higher percentage of them said were they prepared to use the computer as a teaching tool. We emphasize the importance of self-efficacy for the effective use of ICT in the educational context and suggest experiences that can improve its development in training courses.
\end{abstract}

Keywords: Educational Technology, Psychological Variables, Self-efficacy; ICT in Education. 


\section{Introdução}

Uma subárea das Tecnologias da Informação e Comunicação (TIC), a Tecnologia Educativa envolve as aplicações tecnológicas ao contexto educacional para as mais diversas finalidades, como, por exemplo, aquelas relacionadas às questões administrativas ou às relacionadas ao processo de ensino-aprendizagem [1].

O governo brasileiro, desde a década de 80, vem investindo em projetos que visam à aplicação da tecnologia à Educação [2]. Atualmente, destaca-se o Programa Nacional de Tecnologia Educacional (ProInfo Integrado), que é oferecido pelo MEC e tem como objetivo promover a utilização dos computadores no contexto pedagógico em escolas públicas de educação básica e formar professores e gestores para a utilização didático-pedagógica das TIC.

De acordo com dados do Censo Escolar do ano de 2010, 32,3\% das escolas dos anos iniciais do Ensino Fundamental possuíam laboratório de informática, sendo que $38,9 \%$ destas tinham acesso à internet. Dentre as escolas voltadas para os anos finais do Ensino Fundamental, 67,6\% tinham laboratório de informática, 70\% delas com acesso à internet [3].

Lopes [2] realizou uma pesquisa sobre o uso dos computadores em 400 escolas públicas de Ensino Fundamental e Médio de 12 capitais brasileiras. Os resultados evidenciaram como principais problemas para o uso dos computadores o número insuficiente de computadores ou computadores defeituosos $(39 \%)$ e a falta de professores especializados em informática educativa (44\%). Apenas $29 \%$ dos participantes disseram que já foram ministrado cursos de formação em TIC nas escolas onde trabalham.

Na investigação de Lopes [2], o uso dos computadores e da internet foi categorizado em 6 níveis, sendo que quanto maior o nível, maior a adequação do uso para finalidades educativas. Verificou-se que a maior porcentagem das escolas encontra-se no nível 5, descrito como:

(..) Escolas nas quais professores usam computadores com seus alunos para fins pedagógicos, mas em atividades com pouca complexidade ou que usam recursos simples como ler notícias, copiar conteúdos, visualizar mapas, desenhar, usar editores de texto, calculadora ou planilha eletrônica; (p. 300)

Em pesquisa realizada com 253 professores do Ensino Médio de escolas públicas do município de Campinas-SP, Alvarenga [4] encontrou que 27,09\% já participaram de cursos voltados ao uso didático de tecnologias, $15 \%$ se perceberam altamente confiantes para ensinar utilizando tecnologias computacionais e apenas $8,4 \%$ deles relatou utilizar softwares ou programas educacionais para fins didáticos.

Ao investigar o uso de recursos de Informática Educativa em 33 escolas públicas e privadas da cidade de Belém (PA), Ferreira [5] verificou que $56 \%$ não possui laboratório de informática. Dentre as escolas públicas que possuem laboratório de informática, apenas uma (14\%) faz a integração da informática aos demais conteúdos pedagógicos. Entre as escolas particulares esta porcentagem é de $30 \%$. No que diz respeito à formação docente para o uso das TIC, em apenas $19 \%$ das escolas públicas e $40 \%$ das escolas particulares ocorreu algum investimento em formação dos professores, sendo que na maior parte dos casos consistiu em um pequeno treinamento inicial.

Se por um lado verifica-se um esforço na implementação de Tecnologias Educativas nas escolas brasileiras, por outro, nota-se que sua utilização muitas vezes é deficitária ou inexistente [4] seja porque os equipamentos localizam-se em salas onde alunos e professores não têm acesso, seja por não existirem em quantidade adequada para atender a todos [6] ou mesmo porque os professores não sabem como integrá-los em suas atividades [Ferreira; [7].

Deve-se levar em consideração que a relação entre seres humanos e computadores é complexa e envolve mais do que variáveis externas, como a disponibilidade de recursos e oportunidades de formação. Quando busca-se compreender tal relação também é preciso levar em conta as variáveis psicológicas que mediam este processo. Dentre as quais pode-se mencionar o estilo cognitivo dos indivíduos, as variáveis situacionais, as crenças de autoeficácia, os fatores motivacionais e as percepções quanto a utilidade e facilidade da tecnologia com que se tem contato [10].

O papel do professor na incorporação das novas tecnologias no ensino é "estratégico e fundamental" [7, p. 5]. Tal incorporação demanda a modificação na forma como o docente ministra suas aulas visando conciliar as necessidades dos alunos aos recursos tecnológicos, de forma a garantir que o processo de ensino e aprendizagem seja motivador e eficaz $[8,9]$.

Ertmer e Ottenbreit-Leftwich [11] defendem a influência de quatro fatores no uso das TIC por parte dos professores: o conhecimento significativo quanto a aplicação das TIC em sala de aula, a autoeficácia para o uso didático das TIC, as crenças que o professor possui sobre o processo de ensino e aprendizagem e a cultura.

Mais do que ter conhecimento em relação às estratégias pedagógicas ou aos recursos tecnológicos, é necessário que o professor tenha a crença de que seus comportamentos possam influenciar o processo de aprendizagem 
dos estudantes e de que ele possui capacidade para planejar ações e implementá-las com este objetivo [13]. Desta forma, quando o professor apresenta percepções e atitudes positivas, bem como autoconfiança em relação ao uso de tecnologias, é mais provável que ele utilize-as [10].

A crença de autoeficácia é um constructo chave para a compreensão da motivação dos docentes, uma vez que influencia os objetivos que se pretende alcançar, o esforço empregado nas tarefas, a persistência frente a obstáculos e o enfrentamento de situações de fracasso [15]. Desta forma, entende-se que uma melhor compreensão das crenças de autoeficácia pode agregar elementos significativos na elucidação da intrincada relação entre professores e as TIC.

\subsection{Autoeficácia}

A percepção de autoeficácia diz respeito às “(...) crenças dos indivíduos nas próprias capacidades de organizar e executar os cursos da ação requerida para produzir determinadas realizações" [14, p. 3], Tais crenças orientam a vida das pessoas, consistindo em um alicerce para a ação.

As crenças de autoeficácia são embasadas em quatro principais fontes de informação, por meio das quais as pessoas podem avaliar suas próprias capacidades: experiências diretas, experiências vicárias, persuasão verbal e estados fisiológicos e afetivos [14].

A principal fonte de informações de eficácia é a experiência direta, uma vez que oferece informações precisas sobre como se desempenhar para atingir determinado resultado. A experiência vicária envolve a observação do comportamento do outro, o que constitui uma fonte de transmissão de competências e de comparação para as próprias características. A persuasão verbal tem a utilidade de reforçar as crenças dos indivíduos em relação às próprias capacidades. Por fim, são os estados fisiológicos e afetivos, que permitem às pessoas avaliarem suas capacidades, forças e vulnerabilidades [14].

A autoeficácia é importante por influenciar uma série de crenças e comportamentos tais como o curso de ação que uma pessoa escolhe, o esforço que ela emprega em determinada atividade e a forma como ela encara os fracassos e as dificuldades [14]. Pessoas com um alto senso de eficácia tendem a encarar tarefas difíceis como desafios, apresentam um interesse intrínseco nas atividades, recuperam sua autoeficácia após situações de fracasso e atribuem seu fracasso ao esforço insuficiente e vivenciam sentimentos de serenidade frente a atividades difíceis $[14,15,16]$.

Bandura [14] aponta uma série de evidências da relação entre o senso de eficácia e resultados de desempenho no contexto educacional, seja de alunos, seja de professo- res. As experiências vivenciadas neste contexto afetam as crenças de autoeficácia e estas, por sua vez, influenciam o desempenho nas atividades.

A eficácia docente diz respeito "julgamento que o professor faz das suas capacidades para alcançar os resultados desejados de engajamento e aprendizagem do aluno, até mesmo entre aqueles alunos que possam ser difíceis ou desmotivados", [17, p. 783]. Um elevado senso de eficácia docente relaciona-se a crenças e comportamentos relevantes a promoção de uma motivação adequada dos alunos e facilitadores da aprendizagem $[17,18]$.

As crenças de autoeficácia são específicas aos diversos domínios da atividade docente [17, 18], assim, autoeficácia computacional docente (AECD) refere-se a “(...) a crença do professor em sua capacidade para utilizar tecnologias computacionais ou de informática (...) no processo de ensino e aprendizagem ou para integrar as tecnologias de ensino" [4, p. 39].

Estudos indicam que quanto maior a confiança do professor de que é capaz de utilizar as referidas tecnologias para facilitar a aprendizagem do aluno, maior a probabilidade de que ele as utilize em suas aulas $[4,11,18]$, além disso, um aumento na autoeficácia tende a se relacionar a uma melhor qualidade na performance [16].

Tendo como base as quatro fontes de informação anteriormente citadas, a literatura aponta que autoeficácia pode ser aumentada por meio de estratégias instrucionais que visem o aumento da competência. Dentre as estratégias pode-se mencionar a modelação, estratégias de treinamento, estabelecimento de objetivos e feedback atribucional [16].

Wang, Ertmer e Newby [19] desenvolveram um estudo visando verificar a influência da experiência vicária e do estabelecimento de objetivos na autoeficácia para o uso de tecnologias de professores em formação. Os futuros professores foram divididos em oito grupos e participaram de um curso voltado à integração de tecnologias a educação. Para cada turma foram utilizadas determinadas estratégias instrucionais visando o aumento da autoeficácia para o uso de tecnologia. Os pesquisadores verificaram que os participantes que tiveram contato com experiências vicárias e com experiências que envolviam o estabelecimento de objetivos durante o curso apresentaram um maior aumento na autoeficácia para o uso de tecnologias em relação àqueles que não tiveram contato com estas estratégias.

No estudo realizado no contexto brasileiro por Alvarenga [4], foi encontrado que a autoeficácia computacional docente dos participantes foi média moderada, isto é, "ela não é baixa, nem alta, sinalizando que há situações em o professor ainda não se sente confiante o bastante em suas capacidades" (p. 143). Estes professores indicaram a 
experiência vicária como principal fonte de suas crenças de autoeficácia computacional docente, seguida da persuasão social, experiência direta e estados fisiológicos e afetivos, respectivamente. De acordo com a autora, este resultado pode ser explicado pelo pouco contato dos professores investigados com as tecnologias computacionais.

Ao analisar as relações entre variáveis pessoais e autoeficácia computacional docente, Alvarenga [4] também observou índices mais elevados de autoeficácia computacional docente entre aqueles professores que se sentiam muito apoiados ou apoiados o suficiente para o uso didático da tecnologia, entre aqueles que faziam uso de maior número de recursos de informática para fins educacionais, entre aqueles que acreditavam que as tecnologias podem favorecer o processo de ensino e aprendizagem e entre aqueles que participaram de cursos para o uso didático das tecnologias.

Em suma, a formação de professores visando a utilização de recursos tecnológicos deve contemplar mais do o ensino de habilidades, ela deve ser estruturada levando em conta a construção da confiança dos professores em sua capacidade de utilizar tais recursos um aspecto importante de sua atividade profissional $[11,19]$. Vale ressaltar que a percepção de autoeficácia não substitui as habilidades necessárias para a realização das atividades, ela contribui para que se utilize se estratégias adequadas a sua realização [16].

A contribuição de pesquisadores e educadores na compreensão dos processos que envolvem a aplicação das tecnologias ao processo educacional pode oferecer valiosos subsídios para as políticas públicas [6] e práticas de formação. No Brasil é crescente a produção científica sobre as possibilidades das TIC na Educação, o que pode ser constatado pelas publicações especializadas, como a Revista Brasileira de Informática na Educação e os Anais do Simpósio Brasileiro de Informática na Educação (SBIE) e do Workshop sobre Informática na Escola (WIE). Apesar disto, são poucos os estudos sobre as crenças e motivações dos professores quanto ao uso das TIC no contexto brasileiro.

Diante disto, os objetivos do estudo foram: identificar, descrever e analisar a autoeficácia computacional docente de um grupo de professores, mais especificamente, comparar a autoeficácia computacional docente e variáveis pessoais relacionadas ao uso de computadores entre um grupo de professores que trabalha exclusivamente com um software educativo e outro que ministra disciplinas diversas.

\section{Descrição do estudo}

A coleta de dados foi realizada junto a professores de quatro escolas públicas de Ensino Fundamental de um município de pequeno porte do interior do Estado de São Paulo. O critério de seleção foi a participação da escola em um programa que visa a prevenção ou remediação de dificuldades na aprendizagem de leitura na fase inicial de alfabetização, por meio de um currículo informatizado. $\mathrm{O}$ programa é desenvolvido por meio de uma parceria entre a Secretaria Municipal e a Universidade Federal de São Carlos (UFSCar).

Participaram do estudo 34 professores, sendo 4 do sexo masculino e 30 do sexo feminino. A idade média foi de 37,5 anos, o tempo de formado foi 8,3 anos, todos possuem Licenciatura e a maioria $(88,2 \%)$ leciona no Ensino Fundamental.

Os participantes foram divididos em dois grupos. $\mathrm{O}$ Grupo 1 é formado por 9 professores de reforço (com dedicação de 20 horas semanais). Estes professores são contratados e capacitados para monitorar as atividades individuais que os alunos com dificuldades em leitura realizam no computador, utilizando em um software educativo, o Gerenciador de Ensino Individualizado (GEIC), desenvolvido pelo Laboratório de Estudos do Comportamento Humano (LECH) e pelo Laboratório para a Inovação em Computação e Engenharia (LINCE), ambos da UFSCar [21]. Os professores são supervisionados por pesquisadores da UFSCar.

O grupo 2 é formado por 25 professores de turmas regulares que ministram disciplinas diversas (Português, Matemática, História, Ciências, Educação Física, Espanhol, Inglês e Polivalente).

Os instrumentos utilizados para a coleta de dados foram:

- Questionário de caracterização do participante [4]: este instrumento é constituído de 33 questões abertas e fechadas que visam levantar informações sociodemográficas, informações sobre a atuação docente e a utilização de tecnologias de informática dentre os participantes.

- Escala de autoeficácia para o uso de computador: desenvolvida por Wang, Ertmer e Newby [19] e traduzida e adaptada para o contexto brasileiro por Alvarenga e Azzi [22], esta escala visa identificar o nível de autoeficácia de professores para utilizarem tecnologias de informática no ensino. Ela é composta de 21 itens, cujas respostas encontram-se em uma escala Likert de 6 pontos ( $1=$ totalmente falso; $6=$ Totalmente verdadeiro). De acordo com análise fatorial os itens da escala podem ser agrupados em dois fatores: Fator 1 Capacidades e Estratégias em Tecnologias Computacionais (Itens 1, 2, 3, 4, 5, 6, 7, 8, 9, 10, $11,12,13,14,16$ e 18) e Fator 2 - Influências externas no uso de tecnologias computacionais 
(Itens 15, 17, 19, 20 e 21) [4]. Foi realizado um teste de consistência interna para os dados coletados por ocasião deste estudo e obtiveram-se os seguintes coeficientes de confiabilidade: 0,98 para os itens do Fator 1 e 0,93 para os itens do Fator 2. No estudo de Alvarenga [4] foram realizados procedimentos para validação da escala em termos de conteúdo e construto, além disso verificou-se alta consistência interna $(\alpha>0,8)$.

Após a autorização da Secretaria Municipal de Educação, a pesquisa foi submetida ao Comitê de Ética em Pesquisa em Seres Humanos da UFSCar, tendo sido aprovada (Parecer $n^{\circ}$ 431/2011).

A pesquisadora esteve em cada uma das escolas, onde, após o consentimento dos respectivos diretores, explicou os detalhes da pesquisa aos professores, coletivamente, durante o intervalo das aulas. Nesta ocasião foi entregue o Termo de Consentimento Livre e Esclarecido e os instrumentos de coleta de dados àqueles professores que aceitaram participar da pesquisa. Foi combinado que a pesquisadora retornaria dentro de três dias para recolhêlos.

Os dados foram analisados utilizando-se o software Statistical Package for Social Science (SPSS 19.0). Foi realizada uma análise descritiva das variáveis pessoais (frequências e porcentagens das repostas) e uma análise descritiva dos dados obtidos por meio da escala (médias e desvio padrão) de modo a permitir uma comparação das respostas apresentadas pelos dois grupos. Também foi feita uma análise comparativa das médias dos dois grupos para o instrumento de autoeficácia por meio do Teste de Mann-Whitney. Este teste foi escolhido porque a amostra não apresentou uma distribuição normal (Teste de Shapiro-Wilk: $\mathrm{p}=0,002)$. Foi adotado o nível de significância de $5 \%(\mathrm{p}<0,05)$.

\section{Resultados}

A maioria dos professores $(77,8 \%$ do Grupo 1 e $91,7 \%$ do Grupo 2) acredita que as tecnologias de infor- mática podem favorecer o processo de ensino e aprendizagem. Ao serem questionados sobre o quanto sentem-se preparados para a utilização das tecnologias de informática nas aulas, $11,1 \%$ dos professores do Grupo 1 e $28 \%$ responderam estar pouco preparados e $77,8 \%$ dos professores do Grupo 1 e $64 \%$ dos professores do Grupo 2 disseram estar preparados o suficiente.

Quando perguntados sobre a infraestrutura tecnológica disponível à atividade docente, 11,1\% dos professores do Grupo 1 e $88 \%$ dos professores do Grupo 2 disseram ser insuficiente. Ao serem questionados sobre o quanto sentem-se apoiados pelo corpo administrativo da escola para a utilização de recursos de informática no ensino, $33,3 \%$ dos professores do Grupo 1e $25 \%$ do Grupo 2 disse ser pouco apoiado e 55,6\% dos docentes do Grupo 1 e 58,3\% daqueles do Grupo 2 afirmaram que sentem-se suficientemente apoiados.

Todos os participantes têm computador em casa, sendo que $73,5 \%$ o tem há mais de 3 anos. Dentre os professores do Grupo 1, 77,8\% já realizou cursos de informática voltados a programas e aplicativos como aqueles do Microsoft Office (Word, Excel, PowerPoint). Entre os professores do Grupo 2 este percentual foi de $83,3 \%$. Todos os professores do Grupo 1 já participaram de cursos voltados para o uso didático de tecnologias de informática, no entanto, apenas $13 \%$ dos professores do Grupo 2 afirmou já ter realizado cursos com esta finalidade.

A Tabela 1 apresenta as médias e desvios padrões apresentados pelos dois grupos investigados (Grupo 1: trabalha com software educativo e Grupo 2: não trabalha com software educativo) para cada um dos 21 itens da Escala de autoeficácia para o uso do computador. A tabela também apresenta o valor $p$ da comparação dos escores para os diferentes grupos.

Os escores podiam variar de 1 a 6 , sendo que um maior escore representa uma maior autoeficácia para o uso do computador.

\begin{tabular}{|c|c|c|c|c|c|c|}
\hline \multirow[t]{2}{*}{ Fator } & \multirow[t]{2}{*}{ Item } & \multicolumn{2}{|c|}{$\begin{array}{c}\text { Grupo } 1 \\
(N=9)\end{array}$} & \multicolumn{2}{|c|}{$\begin{array}{c}\text { Grupo } 2 \\
(\mathrm{~N}=25)\end{array}$} & \multirow[t]{2}{*}{$\mathrm{p}$} \\
\hline & & M & $d p$ & M & $d p$ & \\
\hline \multirow{3}{*}{ Fator 1} & $\begin{array}{l}\text { 1-Eu me sinto confiante de que entendo de informática, } \\
\text { bem o suficiente, para usar o computador da melhor forma } \\
\text { nas minhas aulas. }\end{array}$ & 5,00 & 0,70 & 4,00 & 1,44 & 0,072 \\
\hline & $\begin{array}{l}\text { 2- Eu me sinto confiante de que tenho as habilida- } \\
\text { des necessárias para ensinar usando o computador. }\end{array}$ & 5,11 & 0,60 & 4,12 & 1,48 & 0,094 \\
\hline & $\begin{array}{l}\text { 3- Eu me sinto confiante de que sou capaz de usar apropria- } \\
\text { damente as tecnologias para ensinar com sucesso os conteú- } \\
\text { dos. }\end{array}$ & 5,22 & 0,66 & 4,04 & 1,45 & 0,024 * \\
\hline
\end{tabular}


4- Eu me sinto confiante em minha capacidade de

avaliar softwares (programas de computador) para ensi- 4,44 1,13 3,52 1,44 0,151 no e aprendizagem.

5- Eu me sinto confiante de que sou capaz de usar a termi-

nologia de informática correta quando oriento os alunos a 4,89 0,78 3,76 1,53 0,079 usarem o computador.

6- Eu me sinto confiante de que sou capaz de ajudar os 5,22 0,83 4,32 0,94 0,027* alunos quando eles têm dificuldade com o computador.

7- Eu me sinto confiante de que sou capaz de monitorar bem

os alunos no desenvolvimento de projetos que envolvem o uso 5,11 0,60 3,96 1,45 0,033* do computador em minhas aulas.

8 - Eu me sinto confiante de que sou capaz de motivar meus

alunos a participarem de projetos que envolvem o uso de 5,33 0,70 4,56 1,12 0,086 tecnologias de informática.

9 - Eu me sinto confiante de que sou capaz de orientar os 5,00 1,11 4,16 1,54 0,175 alunos a usarem as tecnologias apropriadamente.

10-Eu me sinto confiante de que sou capaz de usar

regularmente as tecnologias de informática nas minhas 5,00 1,00 3,96 1,33 0,033* aulas de maneira eficaz.

11-Eu me sinto confiante de que sou capaz de for-

necer feedback ou orientação individual para os alunos 4,67 1,00 3,96 1,56 0,335 durante o uso de tecnologias.

12-Eu me sinto confiante de que sou capaz de in-

cluir tecnologias nas minhas aulas sempre que percebo 5,11 1,05 4,12 1,45 0,055 que é apropriado para a aprendizagem dos alunos.

13-Eu me sinto confiante em selecionar as tecnologias
de informática apropriadas para o ensino de acordo $5,11 \quad 0,78 \quad 4,12 \quad 1,48 \quad 0,072$
com os conteúdos que devem ser ensinados.
com os conteúdos que devem ser ensinados.

14-Eu me sinto confiante em solicitar e avaliar pro-

jetos desenvolvidos, pelos alunos, utilizando-se de tecno- 5,11 0,60 4,16 1,54 0,130 logias.

16-Eu me sinto confiante em relação a usar recursos tecnológicos (como planilhas, portifólios eletrônicos, etc) para coletar e analisar dados de trabalhos e 4,44 1,13 3,56 1,53 0,316 provas dos alunos (ex: resultados, atividades propostas) com o objetivo de melhorar as minhas práticas de ensino.

18-Eu me sinto confiante de que sou capaz de corresponder às necessidades dos alunos durante a utilização 4,67 1,00 3,96 1,51 0,188 do computador.

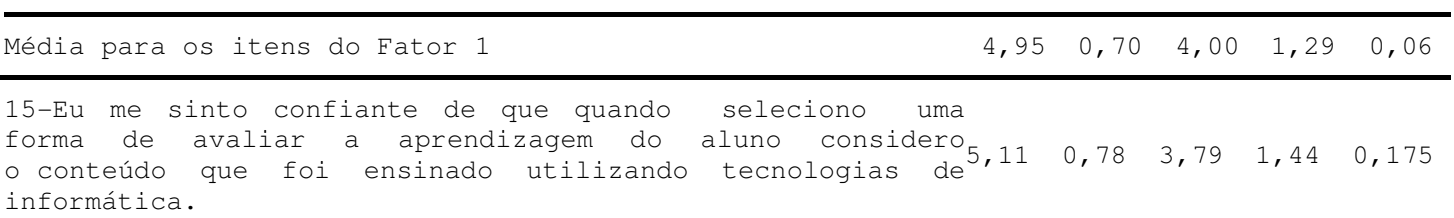

Fator 2 17-Eu me sinto confiante de que sou capaz de me sentir a vontade ou confortável (ex.: sem preocupação, ansiedade ou4,78 0,83 3,92 1,44 0,009* medo) durante o uso de tecnologias em minhas aulas.

19- Eu me sinto confiante de que minha capacidade de atender as necessidades dos meus alunos em relação5,22 0,83 4,44 1,60 0,263 as tecnologias melhorará continuamente. 


\begin{tabular}{|c|c|c|c|c|}
\hline $\begin{array}{l}\text { 20- Eu me sinto confiante de que sou capaz de desenvolver } \\
\text { formas criativas de lidar com restrições do sistema } \\
\text { (tais como cortes de orçamento para aquisição de } 4,67 \\
\text { recursos tecnológicos) e continuar a ensinar bem com tecno- } \\
\text { logia. }\end{array}$ & 0,86 & 3,56 & 1,55 & 0,140 \\
\hline $\begin{array}{l}\text { 21- Eu me sinto confiante de que sou capaz de executar } \\
\text { projetos que envolvem o uso de tecnologias até } 5,11 \\
\text { mesmo quando sou criticado por colegas que duvidam } \\
\text { que isso seja possível. }\end{array}$ & 0,92 & 3,88 & 1,39 & $0,024 *$ \\
\hline Média para os itens do Fator 2 & 0,72 & 3,39 & 1,33 & $0,050 *$ \\
\hline Média total & 0,69 & 3,99 & 1,29 & $0,050 *$ \\
\hline
\end{tabular}

Tabela 1. Média (M) e desvio padrão (dp) dos diferentes grupos para os itens da escala de autoeficácia computacional docente e valor de $p$ para a comparação entre os grupos de professores.

É possível observar que o Grupo 1 apresentou maiores médias para todos os itens da escala, bem como uma média significativamente maior para a soma dos itens do Fator 2 e dos itens totais da escala, indicando que os professores deste grupo apresentam, de modo geral, maior confiança relacionada ao uso do computador no trabalho docente.

As maiores médias foram observadas no item 8 , tanto para o Grupo $1(\mathrm{M}=5.33)$, quanto para o Grupo $2(\mathrm{M}=4.56)$. Isto supõe que os professores apresentam uma alta confiança de que são capazes de motivarem os alunos a participarem de projetos relacionados a tecnologias de informática. Os altos escores para este item podem ser explicados pelo fato de que motivar os alunos não depende dos próprios conhecimentos e habilidades para o uso da informática, nem da infraestrutura disponível na escola.

Em relação ao Fator 1, observa-se que o Grupo 1 apresentou médias significativamente maiores para os itens $3,6,7,10$, indicando que estes professores sentem-se mais confiantes do que os professores do Grupo 2 para utilizar o computador nas aulas, ensinar usando o computador, orientar e monitorar os alunos quanto ao uso do computador.

No que se refere ao Fator 2, o Grupo 1 apresentou médias significativamente mais elevadas para os itens 17 e 21 , dando indícios de que os docentes deste grupo apresentam maior confiança para sentirem-se confortáveis em relação ao uso de tecnologias nas aulas e para executar projetos que envolvem o uso de tecnologias do que os professores do Grupo 2.

O Grupo 1 apresentou médias acima de $5 \mathrm{em}$ 14 dos 21 itens que compõem a escala, indicando que a maioria dos professores deste grupo considera ser totalmente verdadeiro o conteúdo destes itens e demonstrando terem segurança e confiança em diversas situações que envolvem a aplicação das tecnologias educacionais no ensino.

\section{Análise e discussão dos resultados}

Os objetivos do estudo foram comparar a autoeficácia computacional docente e variáveis pessoais relacionadas ao uso de computadores entre um grupo de professores que trabalha exclusivamente com um software educativo e outro que ministra disciplinas diversas.

A maioria dos participantes de ambos os grupos acredita que as tecnologias de informática podem favorecer o processo de ensino e aprendizagem. Isto indica que o uso de tais tecnologias está de acordo com crenças pedagógicas dos docentes, fator que influencia positivamente na utilização de destes recursos $[4,12]$.

Quando um recurso pedagógico é apresentado ao professor, este tende a fazer um julgamento sobre como aquilo pode ser relevante para o seu trabalho e para atingir suas metas em sala de aula. Tal julgamento é baseado em crenças e valores prévios e afetará a forma como o novo recurso será utilizado em seu cotidiano. Assim, é importante que as TIC sejam apresentadas ao professor de forma contextualizada e significativa para que ele possa ter claro como elas se relacionam aos seus objetivos na escola e de que forma podem contribuir na aprendizagem dos alunos $[9,11]$. 
Aproximadamente um terço dos professores do Grupo 1 e um quarto dos professores do Grupo 2 sente-se pouco apoiado pelos gestores da escola para o uso das tecnologias no ensino e aproximadamente metade dos participantes de ambos os grupos sente-se apoiados o suficiente. Vale ressaltar que o contexto cultural, social e organizacional interage com as crenças e valores dos professores e é um outro fator que influencia na utilização do computador. Cada escola e cada grupo de professores compartilha um conjunto de crenças e normas que orientam seus comportamentos e práticas pedagógicas. Desta forma, é provável que o professor não faça uso das TIC se esta não é uma prática bem aceita naquele contexto $[8,9,12]$.

Nas escolas brasileiras, muitas vezes as Tecnologias Educativas são subutilizadas ou inexistentes porque não contam com a infraestrutura adequada $[4,5,6]$. No presente estudo, a maioria dos professores do grupo que não trabalha exclusivamente com software educativo considera a infraestrutura tecnológica disponível na escola insuficiente, indicando que vários destes professores, mesmo considerando a importância das tecnologias no processo educacional e sentindo-se apoiados pelo corpo administrativo da escola, podem não utilizar as tecnologias em suas atividades devido à indisponibilidade ou problemas quanto ao acesso a tais recursos na escola.

A maioria dos participantes já realizou cursos de informática voltados a programas e aplicativos diversos, no entanto, no que diz respeito a cursos voltados para o uso didático de tecnologias de informática, uma minoria de professores do Grupo 2 relatou já terem realizado cursos desta natureza.

De acordo com Ertmer e Ottenbreit-Leftwich [11], o conhecimento sobre as TIC é importante para seu uso, no entanto, saber utilizá-las não garante uma aplicação efetiva em sala de aula, ou seja, pode haver uma distância entre o professor fazer uso das TIC para fins pessoais e para fins didáticos. Utilizar as tecnologias para ensinar requer uma formação sólida, que ofereça subsídios sobre os processos de planejamento, implementação e avaliação, bem como possibilidades de utilização específicas para cada disciplina escolar [5, 7, 9]. Como afirma Elia [8, p. 222], "o que não muda na educação com o uso das modernas TIC é a necessidade de se contar com professores preparados e motivados (...)".
Em relação à autoeficácia, nota-se que, no geral, as médias obtidas pelos dois grupos foram superiores àquelas encontradas no estudo de Alvarenga [4], em que a maior média foi de 4,03 para o item 19 , que diz respeito à capacidade de melhorar continuamente o atendimento às necessidades dos alunos quanto as tecnologias.

Os professores do presente estudo que trabalham exclusivamente com um software educacional apresentaram índices significativamente mais elevados de autoeficácia computacional docente em comparação ao grupo de professores que ministram disciplinas regulares. Isto sugere que experiências pessoais bem-sucedidas no uso de tecnologias educativas podem aumentar a confiança dos professores quanto às próprias capacidades para o uso de tais tecnologias, conforme relatado na literatura $[4,12,19]$.

Cabe destacar que os professores do Grupo 2, além da experiência direta com os recurso educacionais, também tem à disposição outras fontes que podem afetar positivamente suas crenças de autoeficácia, como a possibilidade de acompanhamento da prática bem-sucedida de outros professores que utilizam o mesmo recurso ou a persuasão social, oferecida pelo profissional que acompanha e orienta a implementação do programa no qual trabalham.

Cursos de formação, inicial ou continuada, para o uso de tecnologias na Educação devem abranger não apenas conhecimentos técnicos, mas também levar em conta as variáveis psicológicas, tais como a autoeficácia e suas fontes [4, 6, 22]. Isto pode ser feito, por exemplo, proporcionando aos professores o trabalho com colegas que tenham mais experiência com o assunto, a participação em comunidades de aprendizagem em que seja possível a troca de experiências com outros professores e a vivência de experiências bem-sucedidas desde o começo [11].

Como limitações do presente estudo pode ser apontado o número reduzido da amostra. Estudos futuros poderiam ser realizados com amostras maiores em escolas de diferentes contextos. Uma outra possível limitação é a questão da desejabilidade social, ou seja, pelo fato de que os professores do Grupo 1 são contratados exclusivamente para trabalharem no programa que se utiliza de um software educativo, existe a possibilidade de estes professores terem respondido de forma mais positiva aos 
instrumentos como forma de atender às expectativas que acreditem existir sobre eles.

Estudos futuros poderiam comparar a autoeficácia computacional docente antes e depois de os professores terem realizado cursos voltados ao uso didático do computador e de fazerem uso deste recurso em suas atividades. Sugere-se ainda a realização de estudos que visem a elaboração e avaliação de cursos para formação de professores tendo como base a teoria subjacente às crenças de autoeficácia.

\section{Considerações Finais}

Apesar de serem muitas as possibilidades do uso das TIC no contexto educacional seu potencial vem sendo pouco explorado, privando professores e alunos de alternativas promissoras ao desenvolvimento da aprendizagem. A autoeficácia computacional docente é uma variável psicológica que merece destaque dada sua importância por influenciar o comportamento do professor quanto ao uso do computador. Professores que não acreditam serem capazes de utilizarem os recursos computacionais adequadamente em sua prática profissional, muito provavelmente não os utilizarão.

$\mathrm{O}$ presente estudo encontrou que cursos de capacitação adequados e específicos ao uso de tecnologias na Educação, bem como sua a utilização orientada e bem-sucedida podem favorecer as crenças dos professores quanto às próprias capacidades sobre o uso do computador em suas atividades docentes, aumentando as chances de que ele seja efetivamente utilizado.

Por fim, vale ressaltar que a influência da autoeficácia na utilização de tecnologias na Educação não deve tomada de maneira simplista. Apenas sua promoção não garante esta prática, junto a ela devem ser proporcionadas outras condições que garantam a utilização dos computadores no contexto educacional, para tanto é essencial a parceria entre órgãos públicos e pesquisadores.

\section{Referências}

[1] G.L. MIRANDA, Limites e possibilidades das TIC na educação. Sísifo - Revista de Ciências da Educação, n.3, mai/ago, 2007.
[2] R.D. LOPES, et al. O uso dos computadores e da internet em escolas públicas de capitais brasileiras. Estudos \& Pesquisas Educacionais, n. 1, p. 275- 335, 2010.

[3] MEC/ INEP. Resumo Técnico- Censo Escolar, Brasília-DF, 2010.

[4] C.E.A. ALVARENGA. Autoeficácia de professores para utilizarem tecnologias de informática no ensino. Tese (Doutorado). Faculdade de Educação-Universidade Estadual de Campinas-SP. 2011.

[5] B.DE J.P. FERREIRA Experiências de informática educativa município de Belém: Um quadro inicial de diagnóstico. Revista Brasileira de Informática na Educação, v. 15, n. 1, p. 4549, 2007. Disponível em: http://www.brie.org/pub/index.php/rbie/article/view/61/51 Acesso em: 11/09/12.

[6] M.E.B. ALMEIDA. Gestão de tecnologias, mídias e recursos na escola: o compartilhar de significados. Em aberto, v. 22, n. 79, p. 75-89, 2009.

[7] K. MARCON; A.C. TEIXEIRA. Inclusão digital como base metodológica na formação de professores: um estudo de caso. In: Anais do XXI Simpósio Brasileiro de Informática na Educação. João Pessoa- PB, 23 a 26 de novembro de 2010. Disponível em: http://www.ccae.ufpb.br/sbie2010/anais/Artigos _Completos.html Acesso em: 12 setembro 2012.

[8] M.F. ELIA O papel do professor diante das inovações tecnológicas. In Anais do XXVIII Congresso da SBC, WIE - Workshop sobre informática na escola. Belém do Pará, 12 a 18 de julho de 2008. Disponível em: http://www.brie.org/pub/index.php/wie/article/view/980/966 Acesso em: 12 setembro 2012.

[9] J.A. VALENTE. Criando ambientes de aprendizagem via rede temática: experiências na formação de professores. In: VALENTE, J.A. (org.). Formação de educadores para o uso da informática na escola. Campinas, SP: UNICAMP/ NIED, 2003.

[10] H. HOLDEN; R. RADA. Understanding the influence of perceived usability and technology self-efficacy on teachers' technology acceptance. Journal of Research on Technology in Education, v. 43, n. 4, p. 342-367, 2010.

[11] P.A. ERTMER; A.T. OTTENBREITLEFTWICH. Teacher technology change: How knowledge, confidence, beliefs, and culture 
intersect. Journal of Research on Technology in Education, v. 42, n. 3, 2010.

[12] P.R. ALBION. Some factors in the development of self-efficacy beliefs for computer use among teachers education students. Journal of Technology and Teacher Education, v. 9, n. 3, p. 321347, 2001.

[13] R.G.AZZI; S.A.J. $\quad$ POLYDORO; J.A.BZUNECK. Auto-eficácia proposta por Albert Bandura: algumas discussões. In: AZZI, R. G.; POLYDORO, S. A. J. (org). Autoeficácia em diferentes contextos. Campinas, SP: Editora Alínea, 2006, p. 9-23.

[14] A. BANDURA. Self-efficacy: The exercise of control. W.H.Freeman and Company: New York. 1997.

[15] R.G.AZZI; S.A.J. POLYDORO. O papel da autoeficácia e autorregulação no processo motivacional. In: BORUCHOVITCH, E.; BZUNECK, J.A.; GUIMARÃES, S.E.R. (org). Motivação para aprender - Aplicações no contexto educativo. Campinas, SP: Editora Alínea, 2010, p. 1126-144.

[16] D.H. SCHUNK; F. PAJARES. Competence perceptions and academic functioning. In A. J. Elliot, C. S. Dweck (Eds.), Handbook of Competence and Motivation. New York: The Guilford Press.2005, p. 297-317.

[17] M. TSCHANNEN-MORAN; A. WOOLFOLK HOY. Teacher efficacy: capturing an elusive construct. Teaching and Teacher Education, v.7, p.783-805, 2001.

[18] R.G.AZZI; S.A.J. POLYDORO; J.A.BZUNECK. Considerações sobre a autoeficácia docente. In: AZZI, R. G.; POLYDORO, S. A. J. (org). Autoeficácia em diferentes contextos. Campinas, SP: Editora Alínea, 2006, p. 149-160.

[19] L. WANG; P.A. ERTMER; T.J. NEWBY. Increasing Preservice Teachers' Self-Efficacy Beliefs for Technology Integration. Journal of Reasearch on Technology in Technology in Education, v. 36, n. 3, p. 231-250, 2004.

[20] A.A. FIDALGO-NETO et al., The use of computers in Brazilian primary and secondary schools. Computers \& Education, v. 53, p. 677$685,2010$.

[21] LECH- GEIC Gerenciador de Ensino Individualizado. São Carlos. Disponível em: http://geic.ufscar.br:8080/site/index.jsp Acesso em: 10 setembro 2012.
[22] C.E. ALVARENGA; R.G. AZZI. Autoeficácia computacional docente e o uso didático de tecnologias de informática. In: Actas do I Encontro Internacional TIC e Educação. Inovação curricular com TIC. Realizado no Instituto de Educação da Universidade de Lisboa - Portugal no período de 18 a 20/11/2010. http://ticeduca.ie.ul.pt/. Disponível em: http://www.teoriasocialcognitiva.net.br/publicac oes/anais-de-eventos Acesso em: 12 fevereiro 2012. 